\title{
EFFECTS OF INDUCTION OF ANAESTHESIA AND MUSCLE PARALYSIS ON FUNCTIONAL RESIDUAL CAPACITY OF THE LUNGS
}

\author{
A. K. LAwS, B.SC., M.B., B.S., F.F.A.R.C.s."
}

ThE IMPAIRMENT OF OXYGENATion (as evidenced by increased alveolar-arterial gradients) that occurs during anaesthesia and artificial ventilation is well documented. ${ }^{1-6}$ There is little argument that true veno-arterial shunting consequent upon alveolar collapse is an important contributory factor. Most of the evidence for this is indirect, and the presence of alveolar collapse is inferred from changes in compliance ${ }^{7}$ and from the effect on oxygenation of measures designed to overcome the postulated collapse..$^{5,8-10}$ It would seem more logical to make a measurement directly of lung volume (FRC specifically); however, reports of such measurements during anaesthesia and artificial ventilation have been very few.

Mead and Collier ${ }^{11}$ measured functional residual capacity (FRC) during anaesthesia with spontaneous ventilation and related these changes to changes in compliance. Laver and co-workers ${ }^{12}$ made lung volume measurements in dogs using a body plethysmograph. The only paper reporting measurement of lung volumes during controlled ventilation and anaesthesia in human subjects by a method applicable to clinical situations is that of Déry and co-workers. ${ }^{13}$ Their method was basically a helium dilution technique, but each estimation involved transfer of a volume of gas and two equilibrations; furthermore there is no account of compensation in their system for changing gas components other than helium.

The object of this study was twofold: firstly, to establish a technique for measuring lung volumes during controlled ventilation, and secondly to measure the effect on FRC of induction of anaesthesia and of muscle paralysis. This latter was the initial part of a study planned to investigate changes in FRC during the course of anaesthesia and controlled ventilation.

Using a helium dilution technique, with a spontaneously breathing subject, equilibration of helium within the lung-spirometer system is achieved by the subject's spontaneous ventilatory movements. With artificial ventilation some means of providing gas equilibration and maintenance of ventilation must be incorporated in the circuit. This is most simply done using a self-inflating bag and a valving system. The components of the gas circuit used are shown in Figures 1 and 2 .

The volume estimated by this technique is the volume initially connected to the spirometer. One of the largest sources of random error is the experimenter's beginning the estimation of some volume other than the resting expiratory level. This applies particularly to patients in respiratory failure who may take breaths irregularly while being ventilated. It also becomes of importance when synchronization with a ventilator is required. Having a spirometer within the circuit

"Department of Anaesthesia, University of Toronto. 


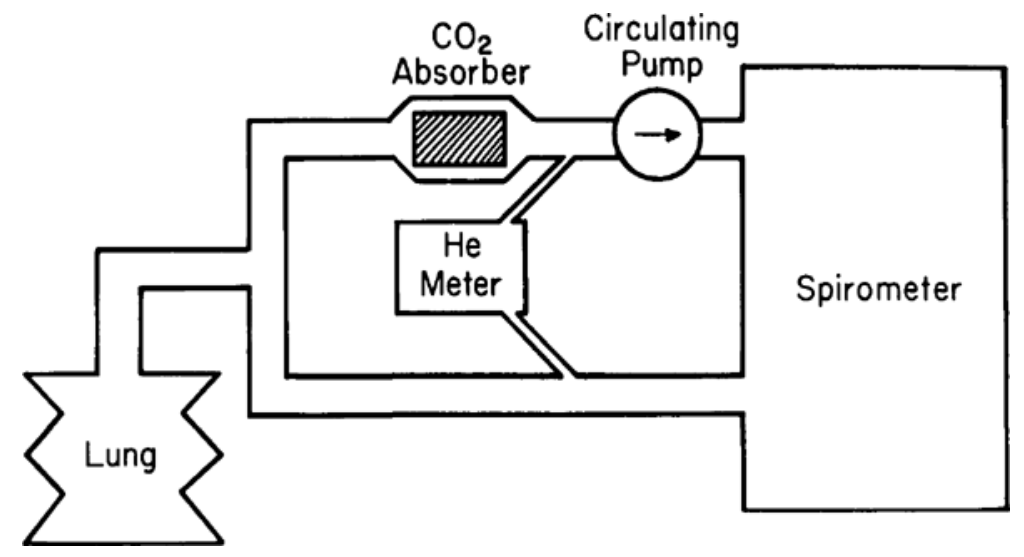

Figure 1. Circuit for determining FRC during spontaneous ventilation.

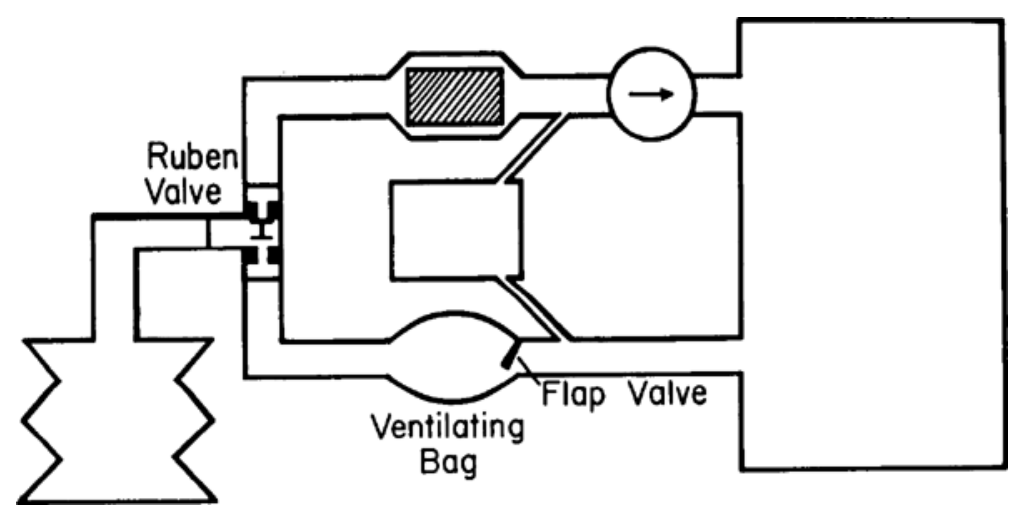

FIGURE 2. Circuit for determining FRC during controlled ventilation.

proves to be a major advantage because if the estimation begins at a level other than the established resting level, appropriate correction can be made. Déry's method was unable to take account of these variations.

What has limited the wide application of this method is the fact that the methods for measuring helium are non-specific. The katharometer essentially senses a difference in thermal conductivity between the gas mixture being sampled and a reference gas (usually air). Therefore, any component appearing in the measurement circuit in different concentration from that in the reference circuit will contribute in part to the over-all meter reading. When making measurements in patients receiving varying concentrations of oxygen and anaesthetic vapours, it is essential to know in what concentration these are present and to what extent these affect the katharometer. Colgan and Whang ${ }^{14}$ have calibrated their instrument both for oxygen with reference to air and for halothane with reference to air. This allows the calculation of that part of the deflection of the katharometer due to helium, provided both oxygen and halothane concentrations are measured. In this study the problem of changing components other than helium was avoided by ventilating the patients at induction with air, by absorbing carbon dioxide, and by replacing oxygen as it was used. 


\section{Apparatus and Method of Measurement}

A Godart helium meter, factory calibrated to give a linear response from 0 to 5 per cent helium and scaled linearly from 0 to 100 , was used, with a $9 \mathrm{~L}$. Collins spirometer modified to obliterate its dead space and to facilitate the addition of both oxygen and helium. Carbon dioxide was removed with soda lime within the spirometer and also within the katharometer. Water vapour was removed in the katharometer with calcium chloride crystals. The output of the helium meter (full scale $=1 \mathrm{mV}$ ) was recorded on a Moseley 10-inch strip chart recorder. In order to limit interference with the recording, a brushless motor was used to drive the circulating fan.

These components along with oxygen and helium cylinders were mounted on a mobile self-contained cart which could be used conveniently in wards, in the operating room; or in the laboratory. A Wright respirometer was inserted between the patient and the Ruben valve to measure the tidal volume resulting from artificial ventilation during the estimation. By eliminating the ventilating bag and valves, the apparatus was made suitable for measuring lung volumes in the spontaneously breathing subject. The fan circulated the gas within the circuit at $40 \mathrm{~L}$./min.; this ensured unidirectional flow of gas and, as valves were eliminated from the system, provided a circuit of low resistance. Thus the circuit was easily adaptable to suit conditions of spontaneous or controlled ventilation, and measurements could be made with essentially the same apparatus before and after induction of anaesthesia.

Oxygen could be added to the circuit through a flow meter at a measured flow determined by oxygen consumption, or it could be added to the constant spirometer volume by means of a switch activating a solenoid valve on the oxygen input line.

The method was validated for both spontaneous and controlled ventilation, as follows. Repeated estimations of FRC were made in the same subject on the same day, with spontaneous ventilation, replacing oxygen as it was used. This gave results with a coefficient of variation of 0.9 per cent. It was impractical to do repeated estimations on a paralysed patient ventilated with air. Therefore a lung analogue was used. No parallel for oxygen consumption could be designed with this set-up without loss of helium at the same time. A known volume was delivered from a calibrated super-syringe into a lung analogue. The added volume was determined after equilibration was reached by ventilating the analogue with the ventilating bag. Repeated estimations yielded results with a coefficient of variation of 0.7 per cent.

\section{ExPERTMENTAL Design}

As the first part of a study of the effect of anaesthesia and controlled ventilation on FRC, the effects of premedication and of induction of anaesthesia with thiopentone and succinylcholine were examined. Eleven patients undergoing elective surgery were studied. Ages ranged from 16 to 59 years. There was no evidence: of cardiopulmonary disease. 
FRC was measured in the supine position with spontaneous ventilation about two hours preoperatively in the ward. Premedication was Pantopon or Demerol and atropine or hyoscine by intramuscular injection; this was given in dosage appropriate for age and physical status 75 minutes preoperatively. A second determination of FRC was made approximately 45 minutes later, again in the ward.

In the operating room 45 minutes later the patient was induced with thiopentone, paralysed with succinylcholine, and intubated without oxygenation or ventilation. The endotracheal tube was connected to the ventilating circuit of the helium-filled apparatus, and equilibration was effected while the patient was ventilated with air and helium. Hypnosis was maintained with intermittent thio pentone intravenously, and paralysis with intermittent succinylcholine, for a period of six to seven minutes.

Correction was made for reduction in dead space with intubation, allowing a volume in cubic centimetres equal to one third of the body weight expressed in pounds. Correction was also made from the spirogram, if the estimation was begun at a point in the respiratory cycle other than the end expiratory point. Volumes were corrected to body temperature and pressure saturated (BTPS).

\section{Results}

The results are shown in Tables I, II, and III. For each patient in each table there is a pair of measurements. The difference between these measurements is expressed as a per cent change of the first reading; a paired $t$-test was then carried out. Data on patients 9,10 , and 11 is incomplete because surgery was postponed.

TABLE I

EFFECT OF PREMEDication ON FRC

\begin{tabular}{ccccccr}
\hline \hline $\begin{array}{c}\text { Patient } \\
\text { no. }\end{array}$ & Sex & Age & Weight & $\begin{array}{c}\text { FRC before } \\
\text { premedication }\end{array}$ & $\begin{array}{c}\text { FRC after } \\
\text { premedication }\end{array}$ & $\begin{array}{c}\text { Per cent } \\
\text { change }\end{array}$ \\
\hline 1 & F & 16 & 130 & 1551 & 1559 & +0.5 \\
2 & M & 34 & 185 & 2550 & 2617 & +2.6 \\
3 & F & 45 & 143 & 1662 & 1603 & -3.5 \\
4 & F & 46 & 105 & 1829 & 1873 & +2.4 \\
5 & M & 59 & 128 & 2992 & 2649 & -11.5 \\
6 & F & 22 & 125 & 1947 & 2092 & +7.4 \\
7 & F & 36 & 172 & 1655 & 1330 & -19.6 \\
8 & M & 26 & 155 & 2444 & 2602 & +6.5 \\
9 & M & 24 & 120 & 1797 & 1548 & -13.9 \\
10 & M & 16 & 120 & 2966 & 3135 & +5.7 \\
11 & & & 2226 & 2048 & -8.0 \\
\hline
\end{tabular}

Mean fall in $\mathrm{FRC}=2.9 \% ; t=1.03$ (10 d.f.) (not significant).

Table I shows that premedication as administered in this study had no significant effect on FRC. The induction of anaesthesia with thiopentone and succinylcholine produced a significant mean fall of 9.0 per cent (Table II). The combined effect of premedication and induction of anaesthesia also produced a significant fall in FRC, the mean fall being 10.8 per cent (Table III). 
TABLE II

Effect of Induction of Anaesthesia on FRC after Premedication

\begin{tabular}{ccccccc}
\hline $\begin{array}{c}\text { Patient } \\
\text { no. }\end{array}$ & Sex & Age & Weight & $\begin{array}{c}\text { FRC before } \\
\text { premedication }\end{array}$ & $\begin{array}{c}\text { FRC after } \\
\text { premedication }\end{array}$ & $\begin{array}{c}\text { Per cent } \\
\text { change }\end{array}$ \\
\hline $\mathbf{1}$ & F & 16 & 130 & 1559 & 1502 & -3.7 \\
2 & M & 34 & 185 & 2617 & 2130 & -18.6 \\
3 & F & 45 & 143 & 1603 & 1354 & -15.5 \\
4 & F & 46 & 105 & 1873 & 1872 & 0 \\
5 & M & 59 & 128 & 2649 & 2377 & -10.3 \\
6 & F & 22 & 125 & 2092 & 1992 & -4.8 \\
7 & F & 48 & 172 & 1330 & 1271 & -4.4 \\
8 & F & 36 & 155 & 2602 & 2218 & -14.8 \\
\hline
\end{tabular}

Mean fall in FRC $=9.0 \% ; t=3.79(7$ d.f. $) ; p<.01$.

TABLE III

Effect of Premedication and Induction of Anaesthesia on FRC

\begin{tabular}{|c|c|c|c|c|c|c|}
\hline $\begin{array}{l}\text { Patient } \\
\text { no. }\end{array}$ & Sex & Age & Weight & $\begin{array}{l}\text { FRC before } \\
\text { premedication }\end{array}$ & $\begin{array}{l}\text { FRC after } \\
\text { premedication }\end{array}$ & $\begin{array}{r}\text { Per cent } \\
\text { change }\end{array}$ \\
\hline 1 & F & 16 & 130 & 1551 & 1502 & -3.2 \\
\hline 2 & $\mathrm{M}$ & 34 & 185 & 2550 & 2130 & -16.5 \\
\hline$\overline{3}$ & $\mathrm{~F}$ & 45 & 143 & 1662 & 1354 & -18.5 \\
\hline 4 & $\mathrm{~F}$ & 46 & 105 & 1829 & 1872 & $\begin{array}{r}+2.4 \\
\end{array}$ \\
\hline 5 & $\mathbf{M}$ & 59 & 128 & 2992 & 2377 & -20.6 \\
\hline 6 & $\mathbf{F}$ & 22 & 125 & 1947 & 1992 & +2.3 \\
\hline 7 & $\mathrm{~F}$ & 48 & 172 & 1655 & 1271 & -23.2 \\
\hline 8 & $\mathrm{~F}$ & 36 & $15 \overline{5}$ & 2444 & 2218 & -9.2 \\
\hline
\end{tabular}

Mean fall in FRC $=10.8 \% ; t=2.96(7$ d.f. $) ; p<.05$.

\section{Discussion}

The method described of measuring FRC during artificial ventilation has several advantages:

(1) Correction can be readily made from the spirometer tracing if the estimation is begun at some volume other than the resting end-expiratory level.

(2) The gas circuit can be quickly changed to suit conditions either of controlled or of spontaneous ventilation.

(3) The circuit can be constructed from readily available standard items.

(4) Correction for helium absorbed during the estimation can be made by extrapolating the straight-line portion of the helium dilution curve back to zero time. The helium concentrations used in these estimations are less than 5 per cent, and the difference in volumes calculated allowing for helium absorption averaged only $50 \mathrm{ml}$.; however, if 10 to 12 per cent helium is used this correction may be of some significance.

(5) By the use of a Wright respirometer between the patient and the Ruben valve, the magnitude of tidal ventilation can be controlled during the estimation. This is relevant from three points of view. (a) If measurements are to be made at intervals during the course of anaesthesia, the magnitude and pattern of tidal ventilation during one estimation may seriously influence subsequent estimations. (b) If respiratory gas collections are to be made following lung volume studies, then a period of over-ventilation or under-ventilation during the estimation could cause significant change in gas exchange until steady state is re-established. (c) If the ventilation during the estimation of FRC were to open up areas of atelectasis, a translocation of gas from the spirometer to the newly expanded areas 
would result. Provided the total volume of lung plus spirometer remains constant (oxygen consumption being replaced at some constant rate, previously measured for that patient), the volume estimated will be that originally connected to the spirometer. If however, constant volume of lung plus spirometer is indicated by a constant spirometer level, and oxygen is replaced to maintain this level, serious error is introduced. Helium is diluted and oxygen concentration in the circuit is increased. The same end results will be seen when there is significant uptake of anaesthetic agent.

The effect of premedication alone on FRC was not significant, although some large falls were recorded in three patients. This wide variation is probably a reflection of individual patient response to a given dosage of preoperative medication. Opiates are known to depress the sigh reflex, and perhaps one might expect a fall in FRC on this basis.

The fall in FRC associated with the induction of anaesthesia as carried out is significant $(p<.01)$. This suggests that the resting end-expiratory position of the spontaneously breathing subject is different from that of the paralysed subject. As the resting end-expiratory position depends on a balance of lung and chest wall forces, the observed fall could be explained by the removal of a muscular component that tends to expand the chest.

It may be that the muscle fasciculations resulting from the action of the depolarizing muscle relaxant are effective in expelling a volume of gas from the lungs, to a level within the expiratory reserve volume. The only information relevant to this point is one case reported by Howell and Peckett, ${ }^{15}$ where no change in the level of the oxygen consumption line, recorded by spirometry, occurred when the muscle relaxant took effect.

The observed changes in lung volume would also result if there were an increase in volume of some cardiovascular compartment within the thorax. However, this possibility was not explored in this study.

It has been suggested that a significant portion of the demonstrated physiological shunt may be due to increased mixed venous desaturation, produced by a fall in cardiac output relative to oxygen consumption. ${ }^{16}$ However, this factor could only become significant in the presence of abnormally large pulmonary shunting. Therefore, some increase in shunt pathways must be postulated, either alone or, much more likely, in combination with a fall in cardiac output in relation to oxygen consumption. Evidence is presented here that a significant fall in FRC (with the implication of atelectasis of some lung units) can occur immediately at the induction of anaesthesia. This is important in the explanation of the aetiology of the large calculated shunt seen early in anaesthesia and in the interpretation of lung volume changes measured later in the course of anaesthesia.

\section{SUMMARY}

A helium dilution method of measuring FRC under conditions of controlled ventilation is described. Using this method the effect on FRC of premedication and of induction of anaesthesia and muscle paralysis has been investigated. No significant change in FRC was found with premedication alone. A significant fall $(p<.01)$ was observed with the induction of anaesthesia and muscle paraly- 
sis. The combined effect of premedication and induction of anaesthesia and muscle paralysis also produced a significant fall in FRC $(p<.05)$.

\section{RÉSUMÉ}

Nous décrivons une méthode de dilution avec de l'hélium pour mesurer la FRC alors que la ventilation est contrôlée. A l'aide de cette méthode, nous avons étudié les effets de la prémédication, de l'induction de l'anesthésie et de la paralysie musculaire sur la FRC. A la suite de la prémédication seulement, nous n'avons pas observé de changement significatif. A la suite de l'induction de l'anesthésie et de la paralysie musculaire, nous avons une diminution significative $(p<.01)$. Les effets associés de la prémédication, de l'induction de l'anesthésie et de la paralysie musculaire ont également entraîné une diminution significative de la FRC $(p<.05)$.

\section{REFERENCES}

1. Campeell, E. J.; Nunn, J. F.; \& Peckett, B. W. A Comparison of Artificial Ventilation and Spontaneous Respiration with Particular Reference to Ventilation-Bloodflow Relationships. Brit. J. Anaesth. 30: 166 (1958).

2. Frumin, M. J.; Bergman, N. A.; Holaday, D. A.; Rackow, H.; \& Salanitre, E. AlveolarArterial $\mathrm{O}_{2}$ Differences during Artificial Respiration in Man. J. Appl. Physiol. 14: 694 (1959).

3. Stark, D. C. \& Smrth, H. Pulmonary Vascular Changes during Anaesthesia. Brit. J. Anaesth. 32: $460(1960)$.

4. Sykes, M. K; Young, W. E.; \& Robinson, B. E. Oxygenation during Anaesthesia with Controlled Ventilation. Brit. J. Anaesth. 37: 314 (1965).

5. Nunn, J. F.; Bergman, N. A.; \& Coleman, A. J. Factors Influencing the Arterial Oxygen Tension during Anaesthesia with Artificial Ventilation. Brit. J. Anaesth. 37: 898 (1965).

6. Bergman, N. A. Components of the Alveolar-Arterial Oxygen Tension Difference in Anesthetized Man. Anesthesiology, 28: 517 (1967).

7. Bendixen, H. H.; Hedley-Whyte, J.; \& Laver, M. B. Impaired oxygenation in Surgical Patients during General Anaesthesia with Controlled Ventilation: A Concept of Atelectasis. New England J. Med. 269: 991 (1963).

8. Bendixen, H. H.; Bullwinkel, B.; Hedley-Whyte, J.; \& Laver, M. B. Atelectasis and Shunting during Spontaneous Ventilation in Anesthetized Patients. Anesthesiology. 25: 297 (1964).

9. Finley, T. N.; Lenfant, C.; HaAb, P.; Puper, J.; \& Rahn, H. Venous Admixture in Pulmonary Circulation of Anesthetized Dogs. J. Appl. Physiol. 15: 418 (1960).

10. Chenex, F. W.; Hornbein, T. F; \& CrawFond, E. W. The Effect of Expiratory Resistance on the Blood Gas Tensions of Anesthetized Patients. Anesthesiology. 28: 670 (1967).

11. MEAD, J. \& Collien, C. Relation of Volume History of Lungs to Respiratory Mechanics in Anesthetized Dogs. J. Appl. Physiol. 14: 669 (1959).

12. Laver, M. B.; Morgan, J.; Bendixen, H. H.; \& Radfond, E. P., JR. Lung Volume, Compliance and Arterial-Oxygen Tensions during Controlled Ventilation. J. Appl. Physiol. 19: 725 (1964).

13. Déry, R.; Pelletien, J.; Jacques, A.; Clavet, M.; \& Houde, J. Alveolar Collapse Induced by Denitrogenation. Canad. Anaesth. Soc. J. 12:531 (1965).

14. Colgan, F. J. \& Whang, T. B. A Method for Measuring Functional Residual Capacity and Dynamic Lung Compliance during Oxygen and Halothane Inhalation. Anesthesiology. 28: 559 (1967).

15. Howell, J. B. L. \& Pecketт, B. W. Studies of the Elastic Properties of the Thorax of Supine Anaesthetized Paralysed Human Subjects. J. Physiol. 136: 1 (1957).

16. Phys-Roberts, C.; Kelman, G. R.; \& Greenbaum, R. The Influence of Circulatory Factors on Arterial Oxygenation during Anaesthesia in Man. Anaesthesia. 22: 257 (1967). 